Editorial

\title{
The Etiology of Möbius Syndrome: A Social Problem?
}

\author{
Geraldo Pereira Jotz ${ }^{1}$ Karine Schwarz ${ }^{2}$ \\ ${ }^{1}$ Morphological Sciences Department, Universidade Federal do Rio \\ Grande do Sul, Porto Alegre, RS, Brazil \\ 2 Neuroscience Postgraduation Program, Universidade Federal do Rio \\ Grande do Sul, Speech Language Pathologist of Voice Institute, Porto \\ Alegre, RS, Brazil
}

Int Arch Otorhinolaryngol 2014;18:227-228.

In this edition, we would like to highlight the article Möbius Syndrome (MS): Misoprostol Use and Speech and Language Characteristics. This study aims to verify speech and language performance of children with MS whose mothers reported use of misoprostol (Cytotec, Pfizer, Connecticut, United States) compared with children with MS from mothers who did not report use. The sample of this study consisted of 18 girls and boys with a previous diagnosis of MS, aged from 4 months to 10 years. The stomatognathic system beyond receptive and expressive language and speech was evaluated in children with MS, and their mothers were questioned whether they used misoprostol during the pregnancy or not. From the total, $61.1 \%$ admitted taking the drug Cytotec at some time during pregnancy, usually in the first few weeks. The researchers concluded that there was a large contingent of women who took misoprostol without knowing its teratogenic action. Moreover, the lack of facial expressions and speech disorders were common characteristics of the individuals with MS, whether the mothers took misoprostol during the pregnancy or not.

MS is described as a very rare disease with just 500 cases reported worldwide by the year $2008 .{ }^{1}$ It is a congenital condition characterized by facial unilateral or bilateral paralysis, complete or incomplete, in association with bilateral palsy of abducens nerve. The child may concomitantly present lingual weakness, and $\sim 30 \%$ of cases present talipes equinovarus (deformity of the feet). It is postulated that this syndrome arises from abnormal development of the seventh cranial nerve, facial muscles, or motor nucleus of the facial nerve; other causes include intrauterine hypoxia. $^{2,3}$ However, other cranial nerves, unilateral or bilateral, may also be involved, causing ptosis, divergent strabismus, deafness, disturbances of sensibility in regions innervated by the trigeminal nerve, dysphagia, dysphonia, and tongue atrophy, which can be verified in different combinations. ${ }^{4}$

Address for correspondence DOI http://dx.doi.org/ Geraldo Pereira Jotz, MD, PhD, 10.1055/s-0034-1383548. Rua Dom Pedro II 891, 604, Porto ISSN 1809-9777. Alegre, RS, Brazil (e-mail: geraldo. jotz@terra.com.br).
Misoprostol is a synthetic drug similar to prostaglandin E1, administered orally for prevention and treatment of gastric ulcer. It is a drug widely used in obstetrics for its uterotonic action and may cause abortion, embryonic death of the fetus, and changes in labor. Although not approved for clinical use by the U.S. Food and Drug Administration, misoprostol is widely used for abortion purposes in Latin America, mainly in Brazil. ${ }^{5-7}$

The popularization of misoprostol as an abortifacient in our environment led to many studies linking the drug as the cause of the increased number of cases of MS in recent years. ${ }^{8,9}$ In a systematic review, aiming to estimate the risk of congenital anomalies and other adverse events in children exposed to misoprostol during fetal life, the authors concluded that prenatal exposure to misoprostol is associated with an increased risk of MS and terminal transverse limb defects. The data source consisted of case-control studies that analyzed the effect of prenatal exposure to misoprostol on pregnancy outcome, which were located in electronic databases and published up to June $2005 .^{9}$

Therefore, the research presented here has great scientific importance to clarify the etiopathogenic aspects of the syndrome as more patients are being studied. Furthermore, the possibility to investigate a larger number of cases expands the opportunity to better characterize clinical conditions, methods of assessment, prognosis, and prevention program development, as well as health promotion of individuals diagnosed with MS.

Geraldo Pereira Jotz

Editor-Chefe

International Archives of Otorhinolaryngology

\section{References}

1 Marambaia O, Gomes A, Marambaia PP, Araujo AH, Almeida FSC. Síndrome de Möebius associada a Misoprostol. Acta Orl 2008; 26(3):169-172

Copyright $\odot 2014$ by Thieme Publicações License terms Ltda, Rio de Janeiro, Brazil

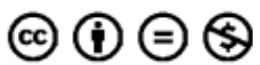


2 Marenda SA, Olsson JE. The evaluation of facial paralysis. Otolaryngol Clin North Am 1997;30(5):669-682

3 Thrasher RD, Cass SP In: Ent Secrets, 2nd ed. Philadelphia, PA: Hanley \& Belfus, Inc.; 2001

4 Fontenelle F, Araujo APQC, Fontana RS. Sindrome de Möebius. Arq Neuropsiquiatr 2001;59(3B):

5 Sánchez O, Guerra D. [Moebius syndrome due to the use of misoprostol. Case report]. Invest Clin 2003;44(2):147-153

6 Costa SH, Vessey MP. Misoprostol and illegal abortion in Rio de Janeiro, Brazil. Lancet 1993;341(8855):1258-1261
7 Coêlho HL, Teixeira AC, Santos AP, et al. Misoprostol and illegal abortion in Fortaleza, Brazil. Lancet 1993;341(8855):1261-1263

8 Corrêa MCDV, Mastrella M. Abortion and misoprostol: health practices and scientific controversy. Cien Saude Colet 2012; 17(7):1777-1784

9 da Silva Dal Pizzol T, Knop FP, Mengue SS. Prenatal exposure to misoprostol and congenital anomalies: systematic review and meta-analysis. Reprod Toxicol 2006;22(4):666-671 